\title{
Treatment of Pentachlorophenol with Manganese Oxide Addition to Biotic and Abiotic Sediments
}

\author{
ROBERT A. PETRIE, JOAN E. MCLEAN, and RONALD C. SIMS \\ Department of Civil and Environmental Engineering \\ Utah Water Research Laboratory \\ Utah State University \\ Logan, UT 84322-8220
}

\begin{abstract}
Laboratory microcosms containing subsamples of a complex environmental sediment were used to evaluate the addition of oxidized manganese as the primary electron acceptor in the presence of pentachlorophenol (PCP) as the primary electron donor. Manganese oxide $\left(\mathrm{MnO}_{2}\right)$ particles were added to poisoned abiotic and non-poisoned biotic microcosms and incubated at $11^{\circ} \mathrm{C}$ in the presence of sediment samples that were shown capable of mineralizing PCP with indigenous microorganisms. Reduction in PCP concentration and production of reduced manganese was measured for both abiotic and biotic systems.

PCP was observed to be transformed most rapidly and to the greatest extent in non-poisoned microcosms. Rate and extent of PCP transformation were increased when $\mathrm{MnO}_{2}$ was added. Rate and extent of PCP transformation were least, but still significant, in abiotic (poisoned) microcosms when $\mathrm{MnO}_{2}$ was added. Reduction in PCP sediment concentration was consistently correlated with an increase in production of reduced manganese $\left(\mathrm{Mn}^{+2}\right)$. The addition of $\mathrm{MnO}_{2}$ was therefore shown to cause a decrease in PCP concentration in a naturally occurring complex environmental sediment. Reduced iron was observed suggesting that both manganese and iron were used as primary electron acceptors. Moreover, higher concentrations of $\mathrm{Mn}^{+2}$ were found in solution than ${ }^{+} \mathrm{Fe}$. This may support thermodynamic evidence that manganese is preferentially used over iron in some redox reactions. Addition of synthetic $\mathrm{MnO}_{2}$ particles via a permeable reaction wall or direct slurry injection, may represent a potential treatment approach for the abiotic as well as biotic reduction of PCP in sediment and ground water environments.
\end{abstract}

\section{INTRODUCTION}

Pentachlorophenol (PCP) is a hazardous constituent present in wood-preserving wastes and is present in contaminated soils and aquifers in the Intermountain West. The U.S. Environmental Protection Agency (US EPA) promulgated a new standard, in 1993, that lowered the drinking water Maximum Contaminant Level (MCL) from $1 \mathrm{mg} / \mathrm{L}$ to $1 \mu \mathrm{g} / \mathrm{L}$ PCP due to concerns about the impact on human health. This action may remove potential drinking water sources from development and will require intensive characterization of contaminated sites for evaluating potential leaching of PCP present at low levels in the subsurface. 
The reactions of chlorinated phenols, including PCP at the surfaces of manganese oxide particles in aqueous suspensions have been shown to involve electron transfer from phenol to Mn (III/IV), resulting in manganese oxide reduction and dissolution [1-5]. Manganese oxides are one of a group of transition metals that have been shown to oxidize both natural and xenobiotic compounds [2, 6-9]. When metal oxides are present, potential pathways are provided for the microbially mediated transport of electrons that is necessary for microbial metabolism. Furthermore metal oxides provide highly reactive surfaces for abiotic catalysis. Manganese oxides are found in many soils and aquifers as layer and tunnel structures [10], and while shown to be reactive with PCP, are not the only sinks for electrons in the subsurface. Oxygen, nitrate, sulfate, iron, and carbon dioxide are additional primary electron acceptors commonly found in subsurface sediments.

A thermodynamic approach to understanding the geochemical (abiotic) alteration of PCP by naturally occurring electron acceptors common to many aquifers may provide a basis for managing geochemical reactions and accomplishing detoxification of PCP to protect groundwater supplies of potable waters [11]. An empirical equation was developed by the authors (unpublished) using recently published Gibbs free energy of formation data [12], to describe stoichiometric reactions of chlorophenols. These results indicate that the solution phase manganese and iron result in higher free energy changes than when oxygen is utilized as a terminal electron acceptor for PCP mineralization. However, manganese and iron in the oxide form yield lower free energy changes than oxygen, but are still energetically favorable. Soluble manganese $\left(\mathrm{Mn}^{+4}\right)$ yields $-44.68 \mathrm{kcal} / \mathrm{eeq}$ and iron $\left(\mathrm{Fe}^{+3}\right)-35.56 \mathrm{kcal} / \mathrm{eeq}$, while oxygen yields $-35.03 \mathrm{kcal} / \mathrm{eeq}$, manganese oxide $\left(\mathrm{MnO}_{2}\right)$ yields $-22.65 \mathrm{kcal} / \mathrm{eeq}$ and iron oxide $(\mathrm{FeOOH})$ yields $-15.77 \mathrm{kcal} /$ eeq. Given the free energy liberated for each of the above reactions, it is relatively easy to calculate the redox potential at which the reaction occurs. However, the redox potential of a disequilibrium system such as the complex environmental sediment used in this study is a function of the poise of the system and the metabolism of microorganisms that induce micro-redox environments. Poising capacity is defined in terms of the amount of strong oxidant needed to change the system redox potential and is a function of the combined concentration of all redox couples present.

Transformations of parent organic compounds are primarily attributed to microbial metabolism rather than abiotic processes [13-17]. However, abiotic catalysis has been shown to be an important factor in the treatment of certain organic wastes $[1-6,8,9,13,19]$.

The goal of the investigation reported in this paper was to determine the reduction in PCP concentration in subsurface sediment upon addition of manganese oxide under abiotic and biotic conditions. Specific objectives of the research included the characterization of the reaction in terms of the loss of PCP through oxidation, manganese IV reduction to manganese II and the rate at which the reactions occur and to determine whether the poise of the system could be altered by addition of manganese oxide.

\section{MATERIALS AND METHODS}

\section{Chemicals}

Unless otherwise noted, all chemicals were analytical grade, commercially available reagents obtained from Fisher Scientific (Santa Clara, Ca) or Aldrich Chemical Co. (Milwaukee, WI) and were used without further purification.

\section{$\underline{\text { Matrix }}$}

A loamy sand sediment from a site in New York was provided by the Electric Power Research Institute (EPRI). This sediment was selected on the basis of 1) known location of PCP contamination, and 2) known presence of PCP degrading microorganisms. PCP was found to have a half life of 46 days and a first order rate constant, $k$ of $1.5 \mathrm{E}-02 \mathrm{~d}^{-1}$ in this sediment under aerobic conditions based upon measurement of PCP mineralization using ${ }^{14} \mathrm{C} \mathrm{PCP}$. This data was collected in a previous study carried out at this institution. Sediment was collected from a depth of $3.7 \mathrm{~m}$ and was near saturation. The sediment was sealed in glass jars and stored at $4{ }^{\circ} \mathrm{C}$. Selected soil sediment properties are given in Table 1. 
TABLE 1. Physico-Chemical Properties of Loamy Sand Sediment from New York Site.

\begin{tabular}{cccccccccc}
\hline Sample & $\mathrm{pH}$ & $\begin{array}{c}\mathrm{EC} \\
\mathrm{mmhos} / \mathrm{cm}\end{array}$ & $\begin{array}{c}\mathrm{P} \\
\mathrm{mg} / \mathrm{kg}\end{array}$ & $\begin{array}{c}\mathrm{K} \\
\mathrm{mg} / \mathrm{kg}\end{array}$ & $\begin{array}{c}\mathrm{NO}_{3}-\mathrm{N} \\
\mathrm{mg} / \mathrm{kg}\end{array}$ & $\begin{array}{c}\mathrm{Mn}^{+2} \\
\mathrm{mg} / \mathrm{kg}\end{array}$ & $\begin{array}{c}\mathrm{Mn}^{+4} \\
\mathrm{mg} / \mathrm{kg}\end{array}$ & $\begin{array}{c}\mathrm{Fe}^{+2} \\
\mathrm{mg} / \mathrm{kg}\end{array}$ & $\begin{array}{c}\mathrm{Fe}^{+3} \\
\mathrm{mg} / \mathrm{kg}\end{array}$ \\
\hline Loamy sand & 8.0 & 0.2 & 15 & 18 & 0.5 & 10 & 0 & 1860 & 199 \\
\hline
\end{tabular}

\section{Oxide Preparation}

Manganese oxide particles were prepared by the method of Whelan [5]. Manganese chloride $\left(\mathrm{MnCl}_{2}\right)$ was oxidized by $\mathrm{KMnO}_{4}$ in a solution of $\mathrm{NaOH}$ under nitrogen purging with gentle stirring. The surface area of the particles was measured using a BET surface-area analyzer and determined to be $161 \mathrm{~m}^{2} / \mathrm{g}$ after 62 days. After 90 days the surface area had decreased to $143 \mathrm{~m}^{2} / \mathrm{g}$. The cation exchange capacity (CEC) was determined by $\mathrm{Mg}^{+2}$ adsorption and found to be $767 \mathrm{mmole}_{\mathrm{c}} / \mathrm{kg}$ at $\mathrm{pH} 2.9$ and 3790 $\mathrm{mmol}_{\mathrm{c}} / \mathrm{kg}$ at $\mathrm{pH} 7.8$. The anion exchange capacity (AEC), determined by $\mathrm{Cl}^{-}$adsorption was 683 mmole $/ \mathrm{kg}$ at $\mathrm{pH} 2.9$ and negative at $\mathrm{pH}$ values greater than $\mathrm{pH} 3.2$. Based upon values determined for $\mathrm{CEC}$ and $\mathrm{AEC}$, the value for the point of zero net charge (PZNC) was determined to be 2.8 [20].

\section{Experimental Microcosms}

Laboratory microcosms were prepared by adding $40 \mathrm{~g}$ of sediment to $40 \mathrm{ml}$ I-CHEM bottles (Figure 1). Amber colored glass was used to minimize the possibility of photodegradation from light during the handling of microcosms. Sediment was rinsed with double deionized water into bottles and filled $(\sim 15 \mathrm{ml})$ leaving no head space. Microcosms were prepared aseptically in an anaerobic glovebox to preclude the intrusion of oxygen. All preparations were made when the glovebox atmosphere was

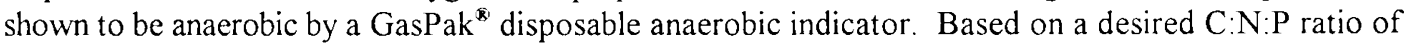
$100: 10: 1$, each microcosm was amended with $0.041 \mathrm{mg}$ of ammonium nitrate and $0.0057 \mathrm{mg}$ of calcium phosphate. Poisoned controls contained $250 \mathrm{mg} / \mathrm{L}(135 \mathrm{mg} / \mathrm{kg}$ wet weight $)$ of mercuric chloride and 500 $\mathrm{mg} / \mathrm{L}(268 \mathrm{mg} / \mathrm{kg})$ of sodium azide as biocides to eliminate microbial activity.

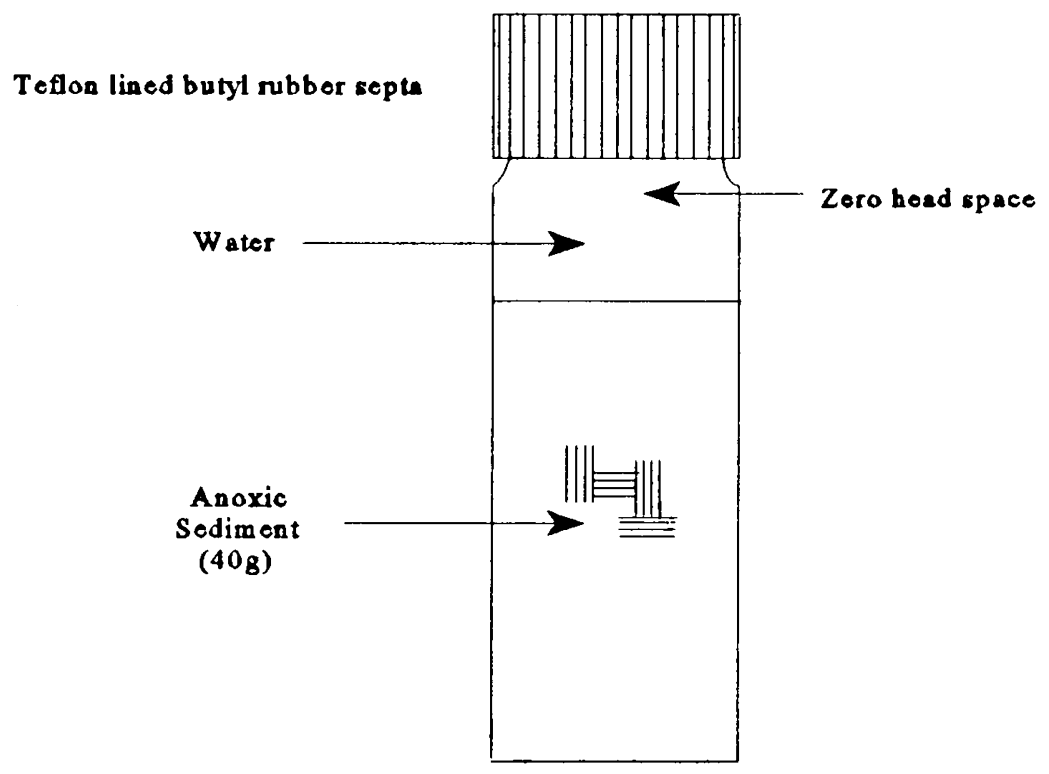

FIGURE 1. Design of Microcosms Using I-CHEM Bottles, Placed in Anaerobic Glove Box. 
TABLE 2. Chemical Treatments Used in Anaerobic Microcosms.

\begin{tabular}{|c|c|c|c|c|}
\hline \multirow[b]{2}{*}{ chemical species added } & \multicolumn{4}{|c|}{ Anaerobic Microcosms } \\
\hline & Biotic & $\mathrm{n}^{\mathrm{a}}$ & Abiotic $^{b}$ & $\mathrm{n}^{\mathrm{a}}$ \\
\hline PCP & $+^{\mathrm{c}}$ & 3 & - & 0 \\
\hline $\mathrm{MnO}_{2}$ & + & 3 & - & 0 \\
\hline $\mathrm{PCP} \& \mathrm{MnO}_{2}$ & + & 3 & + & 3 \\
\hline
\end{tabular}

Four separate treatments were used: biotic microcosms with 1) PCP only, 2) $\mathrm{MnO}_{2}$ only, 3) PCP and $\mathrm{MnO}_{2}$, and 4) abiotic microcosms containing $\mathrm{PCP}$ and $\mathrm{MnO}$ (Table 2). Each microcosm in treatments 1,3 , and 4 was spiked with a solution of PCP to yield a final concentration of $10 \mathrm{mg} / \mathrm{kg}$. Aqueous stock solutions containing $\mathrm{MnO}_{2}$ were used to spike microcosms to yield final solution concentrations of $25 \mathrm{mg} / \mathrm{kg} \mathrm{MnO}_{2}$ where appropriate. Manganese oxide was added to the sediment as a source of oxidizing power because the original sediment sample contained no measurable manganese in the oxidized form and only $9.7 \mathrm{mg} / \mathrm{kg}$ of reduced $\mathrm{Mn}^{+2}$. Immediately after being spiked, the microcosms were sealed with Teflon-lined butyl rubber septa and were mixed and placed in covered containers. Microzosms were incubated in an anaerobic glove box in the dark at $11^{\circ} \mathrm{C}$ to be representative of subsurface conditions.

\section{Sampling}

Three replicates from each treatment were sacrificed after $0,4,9,15$, and 21 days incubation. The aqueous fraction was decanted and filtered $(0.2 \mu \mathrm{m}$ filter $)$ for manganese and iron analysis. PCP was analyzed for in the aqueous fraction at the times 0 and 4 days. No significant PCP was found in the aqueous fraction indicating that PCP readily partitioned onto the solid fraction of the sediment. A two step extraction process, adapted from methods by Lovely and Phillips [15] and Chao [21], was used to remove both reduced and oxidized manganese and iron from the sediments (All inorganic extractions were carried out under anaerobic conditions). It should be noted that the oxidation states of manganese and iron were not determined, the procedures of Lovely and Phillips [15] and Chao [21] are operational definitions of oxidation state based on proven experimental extraction procedures. A $0.5 \mathrm{~g}$ subsample was removed from the microcosm and placed in an acid washed plastic bottle containing $20 \mathrm{ml} 0.5 \mathrm{~N}$ $\mathrm{HCl}$. After 10 minutes on a shaker table, the filtrate was vacuum extracted $(0.2 \mu \mathrm{m}$ filter $)$ for analysis of reduced manganese and iron. The residue remaining on filter paper was digested with $20 \mathrm{ml}$ of 0.25 $\mathrm{N}$ hydroxylamine hydrochloride in $0.25 \mathrm{~N} \mathrm{HCl}$. The sample was mechanically shaken for 40 minutes, after which the sample was vacuum filtered for analysis of oxidized species.

The remainder of the sediment was drained of free water and 20-25 g removed for soxhlet extraction of PCP. The high water content of samples necessitated the use of $80 \mathrm{ml}$ extraction thimbles to accommodate sufficient sodium sulfate for sample drying. Samples were extracted for 18-22 hours with a 50:50 mixture of hexane and acetone. The solvent extract was concentrated using a Kurderna Danish/Synder column apparatus to approximately $3-4 \mathrm{ml}$ volume, then adjusted to $10 \mathrm{ml}$ with acetonitrile.

Analysis.

Manganese and iron analysis was carried out using a Perkin Elmer Inductively Coupled Plasma (ICP)/6000. Manganese and iron were both analyzed at emission spectra of $257.61 \mathrm{~nm}$ and $259.94 \mathrm{~nm}$, 
respectively. Organic analysis of PCP was performed using a Shimadzu High Performance Liquid

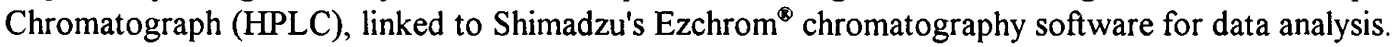
An acetonitrile-water-glacial acetic acid (75:25:0.125) mobile phase using isocratic elution was used at a flow rate of $1.5 \mathrm{ml} / \mathrm{min}$ in conjunction with a $25 \mathrm{~cm}$ Supelco C-18 column. The HPLC was equipped with an ultraviolet (U.V.) detector set at $224 \mathrm{~nm}$. Under the instrument conditions described, PCP had a retention time of $4.40 \mathrm{~min}$.

\section{RESULTS AND DISCUSSION}

The capacity to degrade pentachlorophenol (PCP) varied considerably between treatments (Figure 2). Degradation of $\mathrm{PCP}$ was very rapid in the microcosms containing manganese oxide. Over a period of 21 days, $\mathrm{PCP}$ concentrations were reduced from $2.94 \pm 0.72 \mathrm{mg} / \mathrm{kg}$ to $0.27 \pm 0.05 \mathrm{mg} / \mathrm{kg}$ in the biotic treatment containing added $\mathrm{MnO}_{2}$. Over $90 \%$ treatment of PCP was observed in 3 weeks. The data from Figure 2 were analyzed by zero, first and second order rate kinetics. Good fit of the data to the first order equation indicated that the experimental biotic and abiotic data follow first order kinetics. The first order reaction rate of $9.3 \mathrm{E}-2 \pm 4.1 \mathrm{E}-3 \mathrm{~d}^{-1}$ was the highest of all treatments (Table 3 ), indicating that addition of manganese oxide may significantly enhance the treatment of PCP contaminated soil under anaerobic conditions.

Biotic treatments with no added $\mathrm{MnO}_{2}$ reduced PCP concentrations from $2.89 \mathrm{mg} / \mathrm{kg}$ to $0.82 \pm$ $0.1 \mathrm{mg} / \mathrm{kg}$, equating to over $70 \%$ treatment in 3 weeks. It should be noted that with biotic activity alone, there was approximately a 4 day lag phase before any significant removal of PCP began. Without $\mathrm{MnO}_{2}$ the reaction rate decreased to $5.9 \mathrm{E}-2 \pm 2.7 \mathrm{E}-2 \mathrm{~d}^{-1}$ (Table 3 ).

Abiotic microcosms with added $\mathrm{MnO}_{2}$ reduced PCP concentrations from $3.64 \pm 0.03 \mathrm{mg} / \mathrm{kg}$ to $2.49 \pm 0.26 \mathrm{mg} / \mathrm{kg}$, over $30 \%$ degradation in a 3 week period. The first order reaction rate was $1.9 \mathrm{E}-2$ $\pm 2.8 \mathrm{E}-3 \mathrm{~d}^{-1}$ (Table 3 ).

The results presented here indicate that abiotic degradation under anoxic conditions can be a major pathway for PCP degradation when $\mathrm{MnO}_{2}$ is present. Therefore while abiotic treatment of PCP is significant, biotically mediated treatment of $\mathrm{PCP}$ in the presence of an appropriate electron acceptor such as $\mathrm{MnO}_{2}$ yields the greatest treatment efficiency.

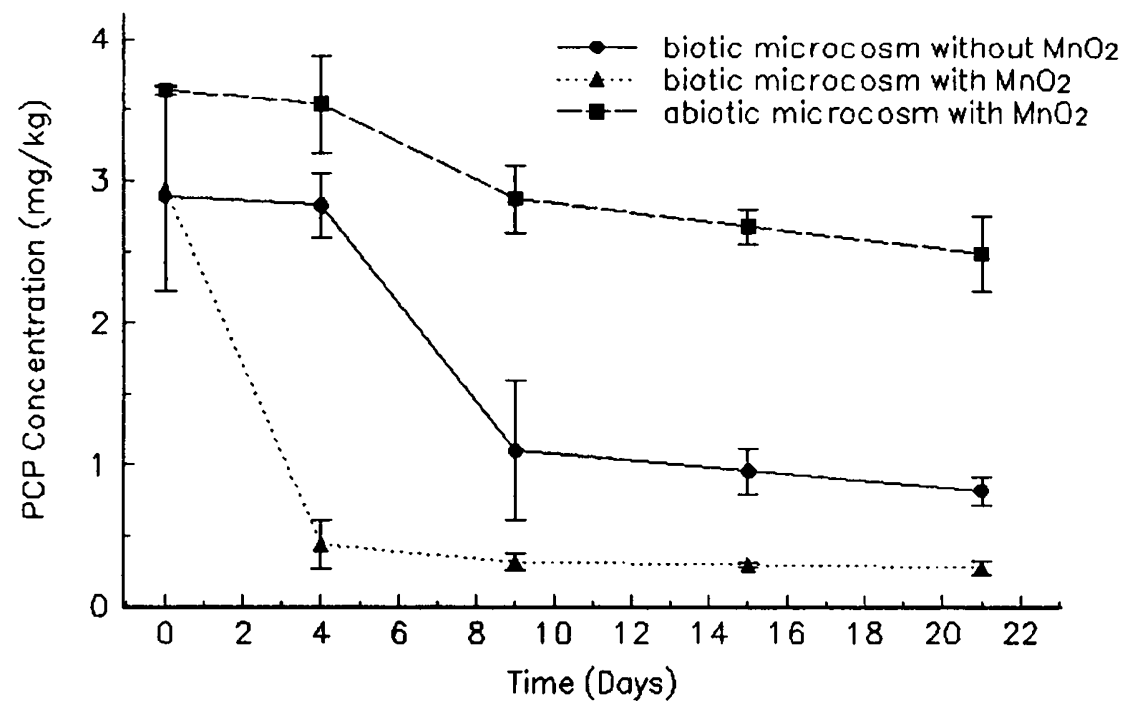

FIGURE 2. Transformation of PCP in Biotic Microcosms without $\mathrm{MnO}_{2}$ addition (๑), with $\mathrm{MnO}_{2}(\boldsymbol{\Delta})$, and in Abiotic (poisoned) Treatments containing $\mathrm{MnO}_{2}(\boldsymbol{\square})$. Mean of Three Replicates with $95 \%$ Confidence Intervals shown. 
TABLE 3. First Order Reaction Rates with $95 \%$ Confidence Intervals.

\begin{tabular}{ccc}
\hline Microcosm & Reaction Rate, $\mathbf{k}\left(\mathbf{d}^{-1}\right)$ & 95\% confidence \\
\hline Biotic without $\mathrm{MnO}_{2}$ & $5.9 \mathrm{E}-2$ & $\pm 2.7 \mathrm{E}-2$ \\
Biotic with $\mathrm{MnO}_{2}$ & $9.3 \mathrm{E}-2$ & $\pm 4.1 \mathrm{E}-3$ \\
Abiotic with $\mathrm{MnO}_{2}$ & $1.9 \mathrm{E}-2$ & $\pm 2.8 \mathrm{E}-3$ \\
\hline
\end{tabular}

The solubility of manganese at higher valence states is low, hence redox reactions must take place at the mineral / water interface. For this reason, overall rates of organic compound oxidation depend upon rates and extent of adsorption to soil matrix or $\mathrm{MnO}_{2}$ as well as upon rates of electron transfer [2]. PCP is often recalcitrant in soils and sediments. At high concentrations $(>80 \mathrm{mg} / \mathrm{kg})$ [22] this recalcitrance is a function of the toxicity of PCP towards microorganisms. When toxicity is not limiting, recalcitrance can be due to the inability of PCP to find a suitable reactive surface. Native minerals are rarely pure, rather they are assemblages of many mineral types. The potential reactive surface area is likely to be considerably less with naturally occurring manganese minerals, hence the same degree of PCP removal may take considerably longer, or may be enhanced by the addition of manganese oxide to the subsurface.

The dissolution of manganese and iron oxides in the experiment described are represented in Figure 3 and Figure 4, respectively. From Figure 3, in $\mathrm{MnO}_{2}$ treatments without PCP addition, no reduced manganese was observed over a 3 week period. A similar result was shown for reduced iron, in fact aqueous concentrations of iron actually decreased from $0.27 \pm 0.07 \mathrm{mg} / \mathrm{L}$ to $0.09 \pm 2 \mathrm{mg} / \mathrm{L}$ (Figure 4). This observation is consistent for sediment that contains little organic matter, hence few electron donors are present. However, it is unusual in that a larger amount of reduced iron did not enter the aqueous fraction from sediment containing $1860 \mathrm{mg} / \mathrm{kg}$ of Fe $\mathrm{F}^{+2}$ and $199 \mathrm{mg} / \mathrm{kg}$ of $\mathrm{Fe}^{+3}$ (extracted in $0.5 \mathrm{~N}$ $\mathrm{HCl})$.

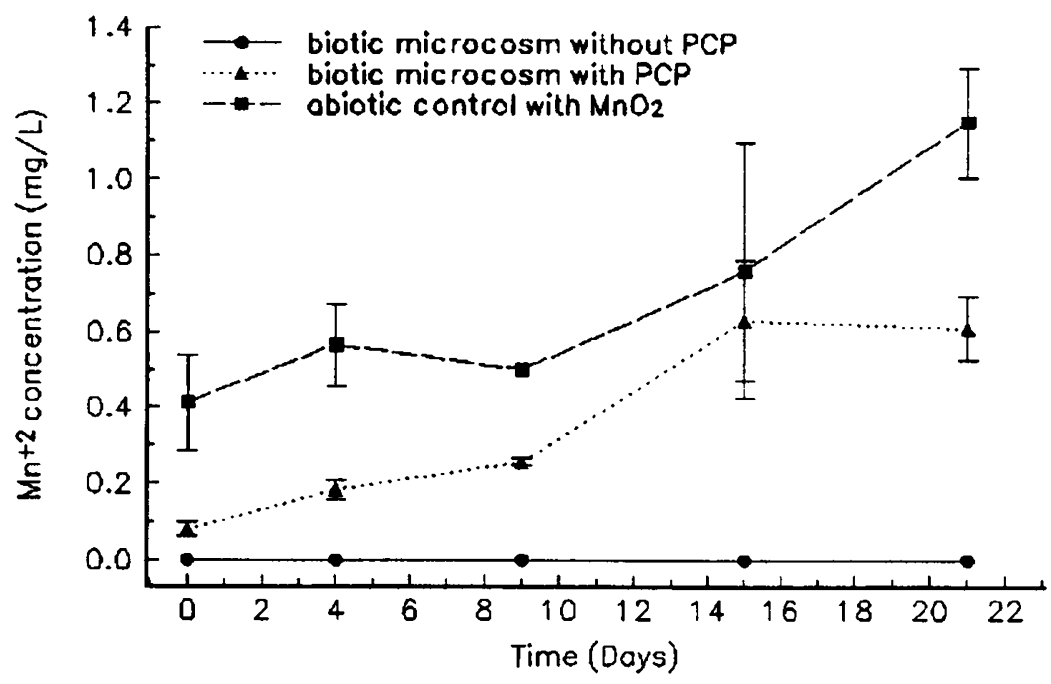

FIGURE 3. Dissolution of Reduced Manganese $\left(\mathrm{Mn}^{+2}\right)$, no PCP addition in Biotic Microcosm (•), with PCP addition to Biotic Microcosms $(\boldsymbol{\Delta})$, and with PCP addition in Abiotic Microcosms ( $\mathbf{\square})$. Mean of Three Replicates with $95 \%$ Confidence Intervals shown. 


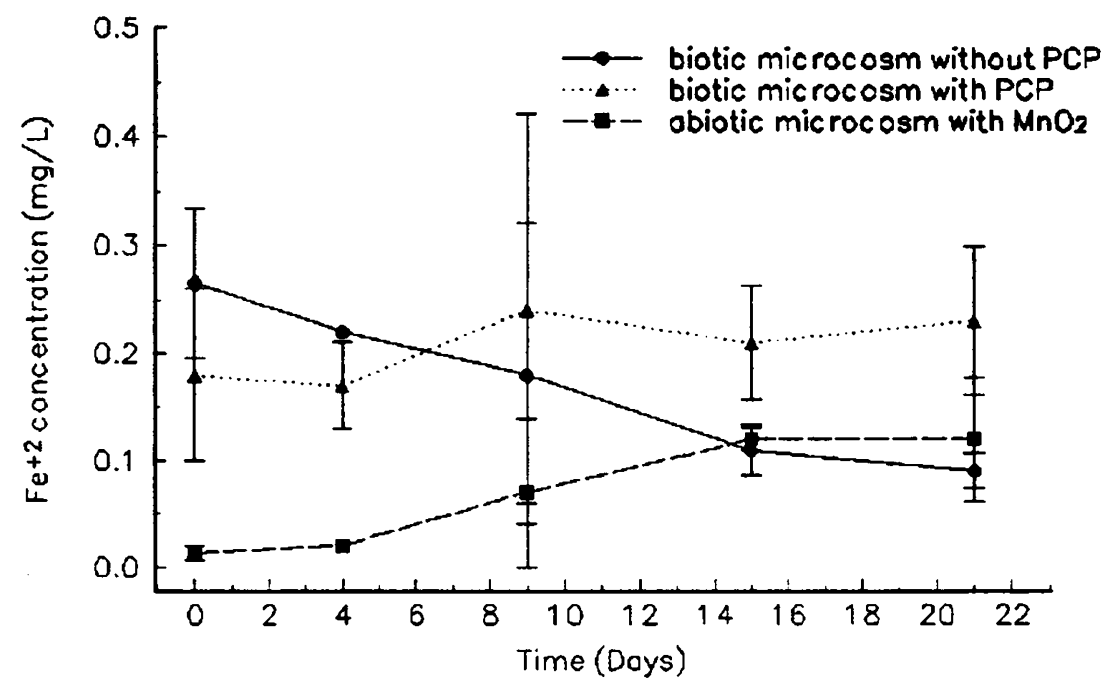

FIGURE 4. Dissolution of Reduced Iron $\left(\mathrm{Fe}^{+3}\right)$, no PCP addition in Biotic Microcosms (•), with addition of PCP in Biotic Microcosms ( $\mathbf{\Lambda})$, and with PCP addition in Abiotic microcosms ( $\boldsymbol{\square})$. Mean of Three Replicates with $95 \%$ Confidence Intervals shown.

PCP, when present in microcosms, provides a potential source of electrons for either the microbial induced and/or abiotic dissolution of manganese and iron oxides. Results indicate that PCP degradation is greatest during the concomitant dissolution of $\mathrm{MnO}_{2}$. Aqueous soluble manganese $\left(\mathrm{Mn}^{+2}\right)$ concentrations increased from $0.08 \pm 0.02 \mathrm{mg} / \mathrm{L}$ to $0.61 \pm 0.09 \mathrm{mg} / \mathrm{L}$ ( $760 \%$ increase) over a 3 week period (Figure 3). Aqueous concentrations of reduced iron increased from $0.18 \pm 0.08 \mathrm{mg} / \mathrm{L}$ to $0.23 \pm$ $0.07 \mathrm{mg} / \mathrm{L}(130 \%$ increase) (Figure 4), which is consistent with the theory that both manganese and iron are being utilized as electron acceptors. Thermodynamic data also suggests that manganese will be preferentially used over iron in redox reactions (unpublished data). Mineralization of PCP in the presence of $\mathrm{Mn}^{+4}, \mathrm{Fe}^{+3}, \mathrm{MnO}_{2}$ and $\mathrm{FeOOH}$ yields free energy changes of $-44.68 \mathrm{kcal} / \mathrm{eeq},-35.56 \mathrm{kcal} / \mathrm{eeq},-22.65$ $\mathrm{kcal} / \mathrm{eeq}$ and $-15.27 \mathrm{kcal} / \mathrm{eeq}$ respectively. Measurements of redox potential throughout the study showed that the potential was never above $-100 \mathrm{mV}$ in any of the treatments. The redox potential of the couple $\mathrm{Fe}$ (II) and $\mathrm{Fe}$ (III) has been measured in soils to be in the range of -150 to $+100 \mathrm{mV}$ [23] and to be as high as $+770 \mathrm{mV}$ in pure solution [24]. At redox potentials below $-100 \mathrm{mV}$, it is unlikely that iron would be oxidized and precipitate out into a less soluble crystalline form during the time of the study.

The abiotic control treatment showed the highest levels of $\mathrm{MnO}_{2}$ dissolution (Figure 3), where aqueous manganese concentrations increased from $0.41 \pm 0.13 \mathrm{mg} / \mathrm{L}$ to $1.15 \pm 0.14 \mathrm{mg} / \mathrm{L}$ during the 3 week study. However, there is some disparity between the concentration of manganese released into solution and the amount of PCP degraded in the abiotic controls ( $>30 \%$ ) (Figure 3 ).

Mercuric chloride and sodium azide were used as biocides in the abiotic treatments. Moreover, both compounds can function as oxidizing agents, which does not explain the apparent increase in manganese dissolution in the abiotic microcosms. The complex nature of subsurface sediments invariably leads to reactions which are unable to be accounted for. Addition of mercuric chloride and sodium azide was the only difference between the abiotic treatment and the biotic treatment containing added PCP and $\mathrm{MnO}_{2}$. Hence these biocides, whether acting together or independently may have been involved in complex series of chemical reactions in which dissolution of $\mathrm{MnO}_{2}$ resulted.

The aqueous concentrations of iron in the abiotic control treatment increased from $0.01 \mathrm{mg} / \mathrm{L}$ to $0.12 \pm 0.06 \mathrm{mg} / \mathrm{L}$ as shown in Figure 4. Compared to the manganese data for the abiotic control treatment and a concentration ratio of iron to manganese of $8: 1$, dissolution of iron contributes little to the degradation of PCP. In fact dissolution of manganese oxide accounts for as much as $86 \%$ of the PCP 
degraded while iron accounts for $14 \%$. The majority of iron present in this sediment is likely part of a mineral consortia, that is the amount of iron surface area available is a function of the crystallinity and grain size of the parent material [25]. If only a small percentage of the crystalline iron surface area is in direct contact with the solution, this might explain why the dissolution effect in the abiotic controls which was observed for manganese, did not solubilize more iron.

Based on the physico-chemical characteristics of the sediment, the amended manganese oxide and native iron were the major terminal electron acceptors. The redox potential of a disequilibrium system is a function of the poise of that system and the metabolism of microorganisms that induce micro-redox environments. Microbial processes related to degradation of xenobiotic organics including PCP are widely accepted as significant pathways. However, when conditions aren't amenable to microbial growth, then the natural poise of the system will be the driving force for any redox reactions. Poising capacity is defined in terms of the amount of strong oxidant needed to change the redox potential of the system [26]. The poise of the sediment is a function of the combined concentration of all redox couples present.

One objective for amending the sediment with $\mathrm{MnO}_{2}$ was to influence the poise, altering it towards the formal potential for the $\mathrm{Mn}^{+4}-\mathrm{Mn}^{+2}$ couple. The formal potential for this couple in soils has been measured between -100 to $+300 \mathrm{mV}$ [23], and in pure solution to be $+1290 \mathrm{mV}$ [24]. Measured potentials ranged from $-550 \mathrm{mV}$ to $0 \mathrm{mV}$ during the course of the experiment, which is considerably lower than the potentials for $\mathrm{MnO}_{2}$ dissolution. Altering the poise is difficult to achieve in a complex mixture such as a soil sample, since the majority of redox couples in natural systems are in a state of internal thermodynamic redox disequilibrium. Instead they are a function of the electron transferring ability of all the redox couples in the system. Consequently, amendments of $\mathrm{MnO}_{2}$ did not result in a measured change in the poise of the system as a whole. However, manganese was reduced with the concomitant degradation of PCP. These results may indicate that the local potential of a thin film surrounding manganese particles was in the region of the $\mathrm{Mn}^{+4}-\mathrm{Mn}^{+2}$ couple. Moreover, the local potential is a function of both microbial activity and localized poise control due to purity of the manganese crystals.

Lindberg and Runnells [27] demonstrated redox disequilibrium in natural waters by comparing numerous field measured redox potential $(\mathrm{Eh})$ values to Eh computed from redox couples using WATEQFC, an equilibrium model used for natural waters. A lack of agreement between data points and the expected locus of points (if all computed redox couples were at internal equilibrium) was found. Unlike the measurement of $\mathrm{pH}$, where the electrode responds directly to the activity of $\mathrm{H}^{+}$ions, redox electrodes do not respond directly to the activity of aqueous electrons but rather to the electron transfer from redox active solutes $[26,28]$.

It was unlikely that any of the treatments would reach chemical equilibrium in the three week period, given the complex mixture of redox couples present. To correlate redox potential measurement with redox couple activity ( $\mathrm{PCP}$ and $\mathrm{MnO}_{2}$ ), redox measurements should not be taken until the system is in chemical equilibrium. This can be achieved in three ways: 1) conduct a longer experiment; 2) simplify the system by removing redox couples that are not of direct interest; 3 ) passively control the redox potential. Longer times are generally impractical simply due to time constraints, but more importantly because of loss of the organic compound. One method for ensuring that only the desired chemical reactions are occurring is to build a more idealized system. Such a system might contain fewer active redox species. In simple systems chemical equilibrium can be achieved relatively quickly. The desired redox potential can be achieved by the addition of gases which readily alter the poise of a system in both the oxidizing and reducing direction. Oxygen is a powerful oxidizing agent and is often used to raise the redox potential $(\leq+500 \mathrm{mV})[29]$ of an aqueous system, conversely nitrogen is often used to achieve reducing conditions $(\geq-150 \mathrm{mV})[29]$. If highly reducing conditions are required, hydrogen can be used to reach redox potentials as low as $-300 \mathrm{mV}[30]$.

The addition of synthetic manganese oxide particles has potential for the treatment of PCP contaminated sediment and groundwater. The pure crystalline manganese oxide used in this study had a very large reactive surface area as a result of its synthetic origin $\left(143 \mathrm{~m}^{2} / \mathrm{g}\right)$. As the oxide matures the surface area decreases towards that of natural oxides. The surface area of synthetically produced manganese oxide decreased from $161 \mathrm{~m}^{2} / \mathrm{g}$ to $143 \mathrm{~m}^{2} / \mathrm{g}$ over a 30 day period. In contrast, native 
manganite $\left(\mathrm{Mn}_{3} \mathrm{OOH}\right)$ and pyrolusite $\left(\beta-\mathrm{MnO}_{2}\right)$ have measured surface areas of $20 \mathrm{~m}^{2} / \mathrm{g}$ and $13 \mathrm{~m}^{2} / \mathrm{g}$ respectively [20]. As a result the potential mineral/water interface for synthetic manganese oxide is very large in comparison to native oxides, hence it is likely that synthetic manganese oxides will be more reactive with PCP than native oxides. Patrick and Henderson [30] observed lowered reactive surface areas of iron minerals resulting from incomplete precipitation. Minerals containing oxides of manganese (III) and manganese (IV) are generally assemblages of compounds, and are rarely pure. Hence, a mineral may contain a large proportion of the compound of interest, but only have a small amount at the reactive surface (mineral/water interface). This implies that rates of reaction with native minerals would be less than those in this study, and that extent of reaction depends on exposure of new reactive surfaces. This may partially explain why the native iron present in relatively high concentrations was not found to be as reactive as manganese oxide in terms of their dissolution chemistry. Because of the large surface reactive nature of synthetic manganese oxide particles enhancing the biotic as well as abiotic degradation of PCP, the addition of $\mathrm{MnO}_{2}$ particles to PCP contaminated sediments may provide a method for the treatment of PCP contaminated groundwater. In situ degradation by a permeable reaction wall (grout wall) is one emerging technology which is showing promising field application. The reactive material consists of iron grindings mixed with concrete sand, and has been consistently getting good results treating halogenated organics [31]. The highly reactive nature of manganese oxide lends itself to this type of technology, but has yet to be tested. Because of the small size $(\sim 1 \mu \mathrm{m})$ of the manganese oxide particles used in this study, they may be suitable for slurry injection into contaminated groundwater, providing that the hydraulic properties of the sediment are conducive to particle transport.

\section{CONCLUSIONS}

Pentachlorophenol was successfully degraded with the concomitant dissolution of added manganese oxide crystals to reduced $\mathrm{Mn}^{+2}$. Microbially mediated degradation appeared to be responsible for the majority of the PCP removal. Over $90 \%$ of the PCP was observed to be degraded in the presence of manganese oxide in biotic microcosms. Abiotic catalysis, which is often regarded as negligible in experimental time frames, contributed to over $30 \%$ of the PCP degradation within a three week period.

Amendments of manganese oxide did not alter the measured poise of the entire system. However, dissolution of manganese oxide to soluble $\mathrm{Mn}^{+2}$ was observed in all treatments indicating that localized potentials surrounding manganese crystals were in the region of the formal potential $(-100$ to $+300 \mathrm{mV})$ for the $\mathrm{Mn}^{+4}-\mathrm{Mn}^{+2}$ couple.

Dissolution of reduced native iron was observed which suggests that both manganese and iron were being utilized as electron acceptors. However, more native iron was present in the sediment than the added manganese oxide (8:1), yet reduced $\mathrm{Mn}^{+2}$ increased $760 \%$ compared to a $130 \%$ increase in reduced $\mathrm{Fe}^{+2}$. This evidence may support the thermodynamic evidence, that manganese is preferentially used over iron (unpublished data). Conversely, high surface area pure manganese oxide is likely to be more reactive than mature native ferrous minerals bound in a mineral consortia.

Because of the reactivity of the high surface area manganese oxide used, the addition to PCP contaminated sediments may provide a basis for the in situ treatment of PCP contaminated groundwater. Manganese oxide could be delivered to the subsurface in the form of a permeable reaction wall, which acts as an interception trench for contaminants or alternatively direct slurry injection by means of conventional pump and treat technology could deliver the reactive oxide directly to the point of contamination. The high surface area of the manganese oxide used for treatment was a major driving force in the degradation of PCP. Rate and extent of redox reactions, whether microbially or abiotically driven, are a function of the mineral to water interface ratio between the electron acceptor (mineral) and the PCP in solution. The mechanism(s) by which biotic processes are able to use electron acceptors, whether by direct metabolism or co-metabolism is still unknown. However, where PCP concentrations are toxic to microorganisms, abiotic treatment may reduce PCP concentrations enough allowing microorganisms to metabolize PCP using manganese oxide as the terminal electron acceptor. 


\section{ACKNOWLEDGMENTS}

This work was supported by the Department of the Interior, U.S. Geological Survey (USGS), through a competitive contract (Grant No. 14-08-0001-G2049 "Geochemical reactions important for characterization and treatment of PCP contaminated Aquifers") to Utah State University, Logan, Utah. Joan E. McLean was the principal investigator. Thanks are extended to Dr. Ishwar Murarka of the Electric Power Research Institute (EPRI) for supplying the sediment used in this study.

\section{REFERENCES}

1. Stone, A.T. (1987). Reductive dissolution of manganese (III/IV) oxides by substituted phenols Environ. Sci. Technol. 21:979-988.

2. Ulrich, H-J. and A.T. Stone (1989). Oxidation of chlorophenols adsorbed to manganese oxide surfaces. Environ. Sci. Technol. 23:421-428.

3. Ukrainczyk, L. and M.B. McBride (1993). The oxidative dechlorination reaction of 2,4,6trichlorophenol in dilute aqueous suspensions of manganese oxides. Environ. Tox. and Chem. v 12:2005-2014.

4. Ukrainczyk, L. and M.B. McBride (1993). Oxidation and dechlorination of chlorophenols in dilute aqueous suspensions of manganese oxides: Reaction products. Environ. Tox. and Chem. v 12:2015-2022.

5. Whelan G. (1992). Surface-induced oxidation of multiple-ringed diol and dione aromatics by manganese dioxide. Ph.D Dissertation. Department of Civil and Environmental Engineering, Utah State University, Logan, Utah.

6. Stone, A.T. and J.J. Morgan (1984). Reduction and dissolution of manganese (III) and Manganese (IV) oxides by organics: 2 . Survey of the reactivity of organics. Environ. Sci. Technol. 18:617-624.

7. Shindo, H. and P.M. Huang (1984). Catalytic effects of manganese (IV), and iron (III), aluminum, and silicon oxides on the formation of phenolic polymers. Soil Sci. Soc. Amer. J., 48:927-934.

8. Laha, S. and R.G. Luthy (1990). Oxidation of aniline and other primary amines by manganese oxide. Environ. Sci. Technol. 24:363-373.

9. Whelan, G. and R.C. Sims (1992). Oxidation of recalcitrant organics in subsurface systems. Haz. Waste Haz. Mat. 9:245-265.

10. McKenzie, R.M. (1989). Manganese oxides and hydroxides. In J.B. Dixon and S.B. Weed, eds., Minerals in the Soil Environments, 2nd ed. Soil Science Society of America, Madison, WI, pp.439-465.

11. McFarland, M.J. and R.C. Sims (1991). Thermodynamic Framework for evaluating PAH degradation in the subsurface. Groundwater 29:885-896.

12. Dolfing, J. and B.K. Harrison (1992). Gibbs free energy of formation of halogenated aromatic compounds and their potential role as electron acceptors in anaerobic environments. Environ.

Sci. Technol. 26:2213-2218. 
13. Murthy, N.B.C., D.A. Kaufman, and G.F. Fries (1979). Degradation of pentachlorophenol (PCP) in aerobic and anaerobic soil. J. Environ. Sci. Health Part B 14:1-14.

14. Lovely, D.R., M.J. Baedecker, D.J. Lonergran, I.M. Cozzarelli, E.J.P. Phillips, and D.I. Siegel (1989). Oxidation of aromatic contaminants coupled to microbial iron reduction. Nature. 339:297-300.

15. Lovely, D.R. and E.J.P. Phillips.(1988). Novel mode of microbial energy metabolism: Organic carbon oxidation coupled to dissimilatory reduction of iron or manganese. Appl. Environ. Microbiol. 54:1472-1480.

16. Cobb, G.D. and E.J. Bouwer (1991). Effects of electron acceptors on halogenated organic compound biotransformations in a biofilm column. Environ. Sci. Technol. 25:1068-1074.

17. Davis, A., J. Campbell, C. Gilbert, M.V. Ruby, M. Bennett, and S. Tobin (1994). Attenuation and biodegradation of chlorophenols in ground water at a former wood treating facility. Ground Water. 32:248-257.

18. Stone, A.T. and J.J. Morgan (1984). Reduction and dissolution of manganese (III) and manganese (IV) oxides by organics. Reactions with hydroquinone. Emviron. Sci. Technol. 18:450-456.

19. Vogel, T.M. and P.L. McCarty (1987). Abiotic and biotic transformations of 1,1,1trichloroethane under methanogenic conditions. Environ. Sci. Technol. 21:1208-1213.

20. Cramer, A.C. (1995). Oxidation of pentachlorophenol with manganese oxide. M.S. Thesis. Department of Civil and Environmental Engineering, Utah State University, Logan, Utah.

21. Chao, T.T. (1972). Selective dissolution of manganese Oxides from soils and sediments with acidified hydroxylamine hydrochloride. Soil Sci. Soc. Amer. Proc. 16:764-768.

22. Ramaprasad, A. (1994). Limitations on biotransformation of pentachlorophenol in soil. M.S Thesis. Department of Civil and Environmental Engineering, Utah State University, Logan, Utah.

23. Patrick, JR., W.H. and A. Jugsujinda (1992). Sequential reduction and oxidation of inorganic nitrogen, manganese, and iron in flooded soils. Soil Sci. Soc. Amer. J. 56:1071-1073.

24. Stumm, W. and J.J. Morgan (1981). In: Aquatic Chemistry: An Introduction Emphasizing Chemical Equilibria in Natural Waters. Editor W. Stumm and J.J. Morgan. John Wiley and Sons Inc. New York pp 780.

25. Birkeland, P.W. (1974). Pedology, Weathering, and Geomorphological Research. Oxford University Press, Inc.

26. Grundl, T. (1994). A review of the current understanding of redox capacity in natural, disequilibrium systems. Chemosphere. 28:613-626.

27. Lindberg, R.D., Runnells, D.D. (1984). Ground water redox reactions: An analysis of equilibrium state applied to Eh measurements and geochemical modeling. Science 225:925927.

28. Hostettler, J.D. (1984). Electrode electrons, aqueous electrons and redox potentials in natural waters. Amer. J. Sci. 284:734-759. 
29. Dragun, J. (1993). An Eh-pH reactor that simulates soil-groundwater systems. J. Soil Contamin. 2:27-36.

30. Patrick, JR., W.H., Henderson, R.E. (1980). Reduction and reoxidation cycles of manganese and iron in flooded soil and in water solution. Soil Sci. Soc. Amer. J. 45:855-859.

31. O'Hannesin, S.F. and Gillham, R.W. (1993). In Situ degradation of halogenated organics by permeable reaction wall. Environmental Protection Agency Ground Water Currents.

EPA/542/N-93/003

Address reprint requests to:

Ronald C. Sims Department of Civil and Environmental Engineering Utah Water Research Laboratory

Utah State University

Logan, UT 84322-8220 